\title{
Estudo comparado da morfologia externa de Zaretis itys itylus (Westwood) e Agrias claudina annetta (Gray) (Lepidoptera, Nymphalidae, Charaxinae). Ill. Abdome ${ }^{1}$
}

\author{
Carlos Guilherme C. Mielke ${ }^{2}$, Olaf H. H. Mielke ${ }^{3}$ \& Mirna M. Casagrande ${ }^{3}$ \\ ${ }^{1}$ Contribuição número 1293 do Departamento de Zoologia, Universidade Federal do Paraná. \\ ${ }^{2}$ Caixa postal 1206, 84145-000 Carambeí, Paraná, Brasil.E-mail: cmielke1@uol.com.br \\ ${ }^{3}$ Laboratório de Estudos de Lepidoptera Neotropical, Departamento de Zoologia, Universidade Federal do Paraná. Caixa \\ Postal 19020,81531-980 Curitiba, Paraná, Brasil. Pesquisador do CNPq. E-mail: omhesp@ufpr.br; mibras@ufpr.br
}

\begin{abstract}
Comparative study of the external morphology of Zaretis itys itylus (Westwood) and Agrias claudina annetta (Gray) (Lepidoptera, Nymphalidae, Charaxinae) III. Abdome. Two species of Charaxinae, Zaretis itys itylus (Westwood, 1850) and Agrias claudina annetta (Gray, 1832) were subject of a detailed and comparative study of external morphology of the abdome. The results obtained were compared with other studies published and related to the external morphology of other Nymphalidae (Brassolinae, Morphinae, Danainae and Ithomiinae) and Lycaenidae.
\end{abstract}

KEY WORDS. Butterflies, comparative study, morphology, Neotropical.

RESUMO. Realizou-se um estudo detalhado e comparado da morfologia externa do abdome de duas espécies de Charaxinae, Zaretis itys itylus (Westwood, 1850) e Agrias claudina annetta (Gray, 1832). Os resultados obtidos foram comparados com outros já publicados e relacionados com morfologia externa de alguns Nymphalidae (Brassolinae, Morphinae, Danainae e Ithomiinae) and Lycaenidae.

PALAVRAS CHAVE. Borboletas, estudo comparado, morfologia, neotropical.

Esta é a terceira contribuição ao estudo morfológico externo e comparado de Zaretis itys itylus (Westwood, 1850) e Agrias claudina annetta (Gray, 1832). Aspectos taxonômicos, material e metodologia utilizados, como mencionados nas contribuições anteriores (MiєLKE et al. 2004a, b).

Muitas são as divergências entre autores quando se trata do primeiro esterno abdominal. Енrцich (1958a) indica uma estreita barra esclerotinizada como esterno I e este fundido ao esterno II; ВRоск (1971) considera esta porção como um esclerito secundário do esterno II; Sorensen (1980) considera como esterno I, com ressalvas, a área membranosa anterior ao esterno II; Casagrande (1979), Bilotta (1994) e Bizarro et al. (2003) indicam um esclerito bem definido como em ЕнrLich (1958a), enquanto para SCoble (1992) o esterno I é ausente nos Heteroneura e presente nos Lepidoptera mais primitivos.

Da mesma forma confusa são tratados os termos gnato e subunco. Para Niculescu (1973) esta confusão pode ser evitada se considerarmos o subunco como estrutura acima do tubo anal e gnato abaixo deste. No entanto, essa forma de interpretação não parece tão fácil, muitas vezes, os braços laterais não se unem ventralmente abaixo do tubo anal, formando placas laterais dirigidas distal, dorsal ou ventralmente. Sorensen (1980) baseado nas conclusões de Ogata et al. (1957) considera gnato e subunco estruras sinônimas. Como gnato foi descrito por PIERCE
(1909) e subunco por Chapman (1911), utiliza-se o primeiro.

Com relação aos termos saco e vínculo, como identificado por Casagrande (1979) e considerando que até a presente data os termos são tratados como estruturas distintas como em Nielsen \& Common (1991), Scoble (1992) entre outros, salienta-se que o próprio Pierce (1909) autor do termo vinculo (vinculum) em publicação posterior, em 1914 (página XXII), o sinonimiza com saco (saccus) de Bethune-Baker (1891).

\section{Zaretis itys itylus (Westwood, 1850)}

Figs 1-16

Abdome composto de 10 segmentos, sendo que no macho os dois últimos estão reduzidos e modificados para a formação de parte da genitália e na fêmea, os três últimos. Nos machos é compacto anteriormente e alargado dorso-ventralmente no primeiro terço; não apresentam estruturas glandulares inseridas na pleura.

Cada um dos segmentos é composto por um tergo e um esterno, ambos esclerotinizados, interligados lateralmente pela pleura membranosa que na máxima altura é maior que a somatória de tergo e esterno. Tergo I composto por porção dorsal onde os dois terços anteriores são membranosos e o posterior é esclerotinizado, retangular e com a porção lateral 


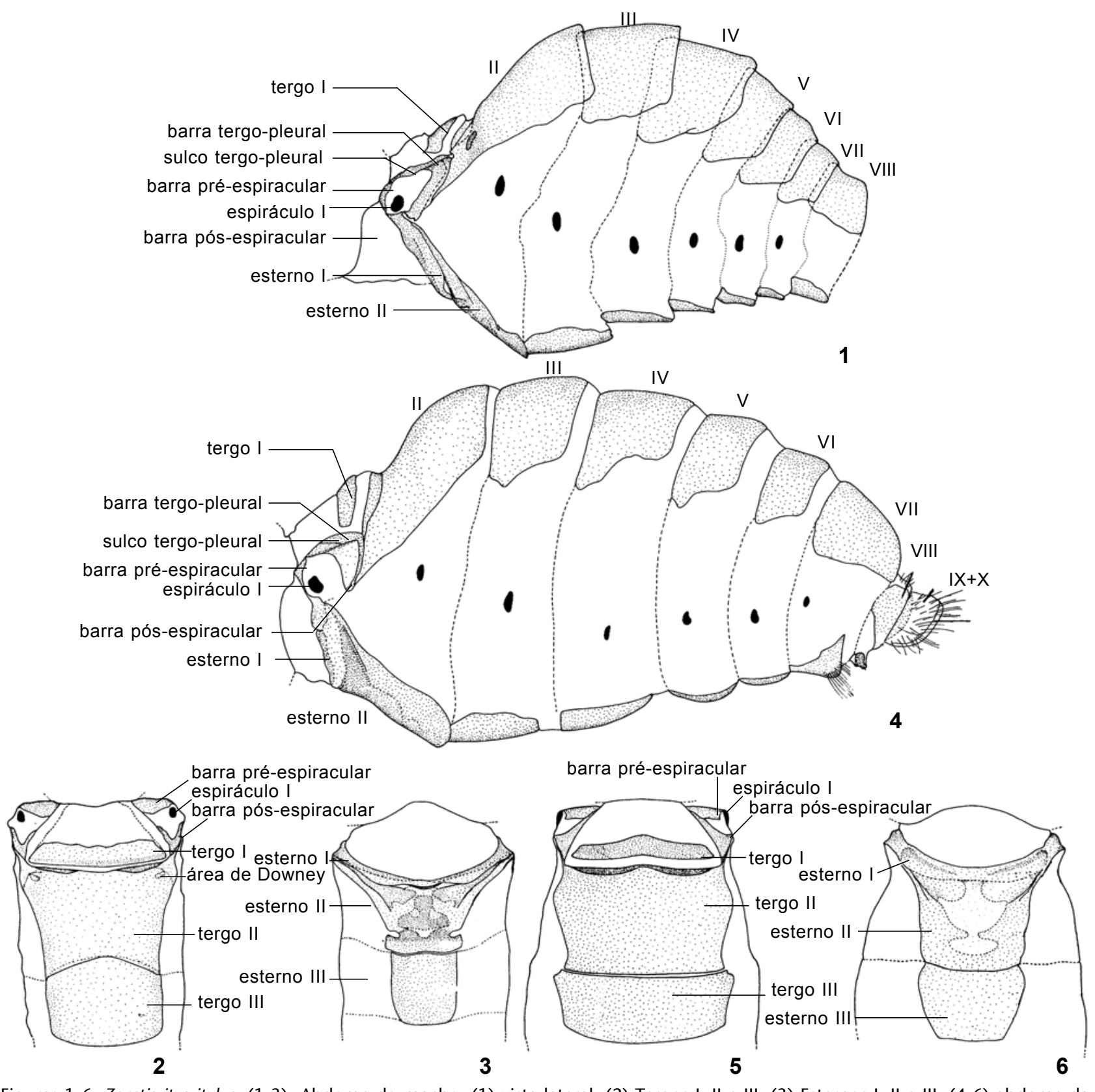

Figuras 1-6. Zaretis itys itylus. (1-3) Abdome do macho: (1) vista lateral; (2) Tergos I, II e III; (3) Esternos I, II e III; (4-6) abdome da fêmea: (4) vista lateral; (5) Tergos I, II e III; (6) Esternos I, II e III.

caracterizada por uma barra horizontal, denominada de barra tergo-pleural, ligada póstero-ventralmente à barra pós-espiracular e anteriormente à barra pré-espiracular. Espiráculo I inserido entre estas três barras. Barra tergo-pleural com uma inflexão denominada de sulco tergo-pleural. Nos machos a barra pós-espiracular desce lateralmente até próximo ao esterno I, o que não acontece nas fêmeas. Esterno I reduzido, projetado desde o ponto de in- serção da barra tergo-pleural até a fusão com o lado oposto, sendo a parte anterior mais esclerotinizada ventralmente; látero dorsalmente, a margem posterior estreita-se para acomodar o espiráculo, este estreitamento define a barra pré-espiracular. Tergo II é o maior esclerito do abdome e apresenta na região ânterodorsal uma inflexão projetada internamente que forma uma parede de margem ventral bilobada, como o primeiro fragma

Revista Brasileira de Zoologia 21 (4): 905-912, dezembro 2004 


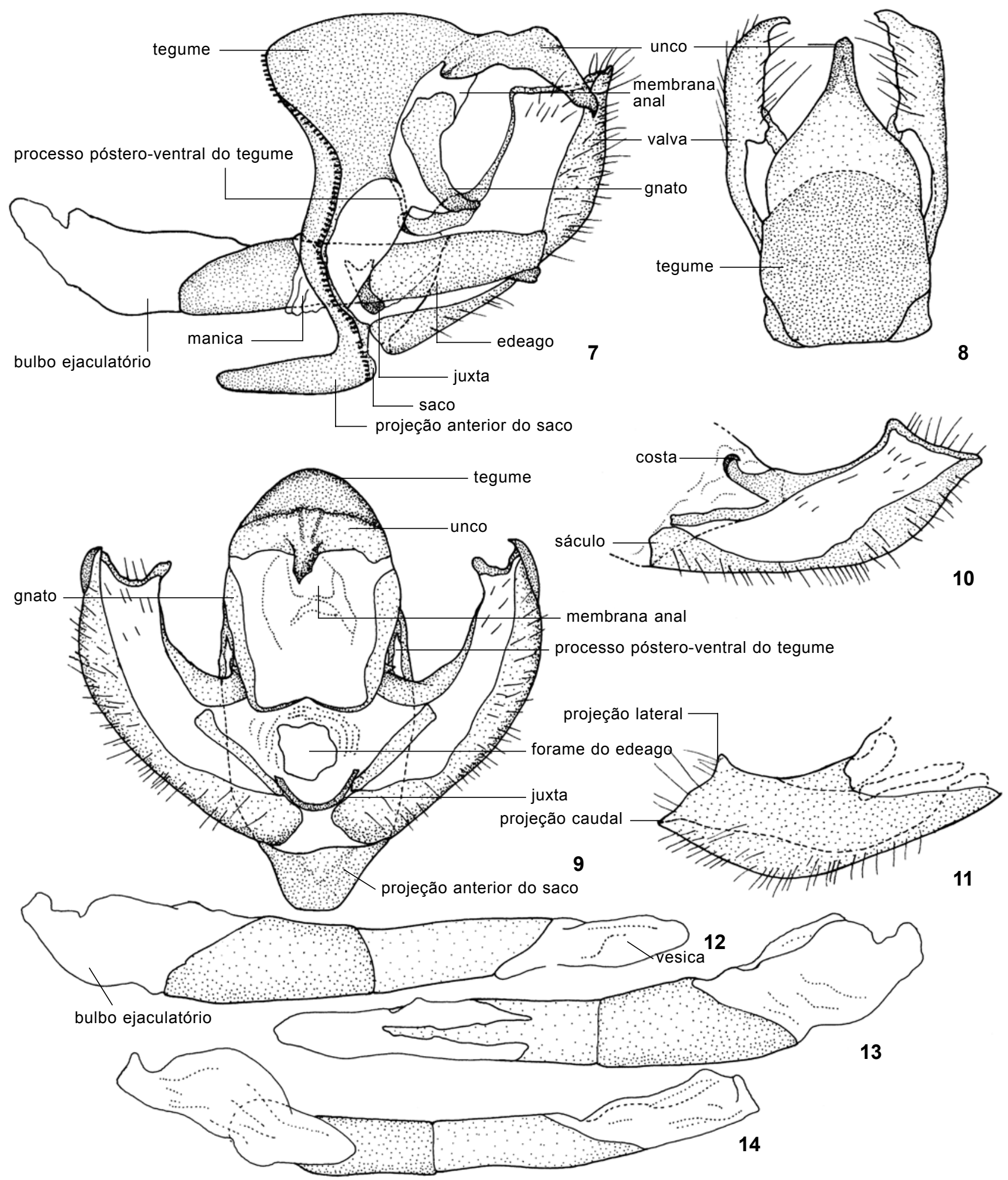

Figuras 7-14. Zaretis itys itylus, genitália masculina: (7) vista lateral; (8) vista dorsal; (9) vista ventral; (10) vista interna da valva; (12) vista externa da valva; (12-14) edeago: (12) vista lateral; (13) vista ventral; (14) vista dorsal.

Revista Brasileira de Zoologia 21 (4): 905-912, dezembro 2004 


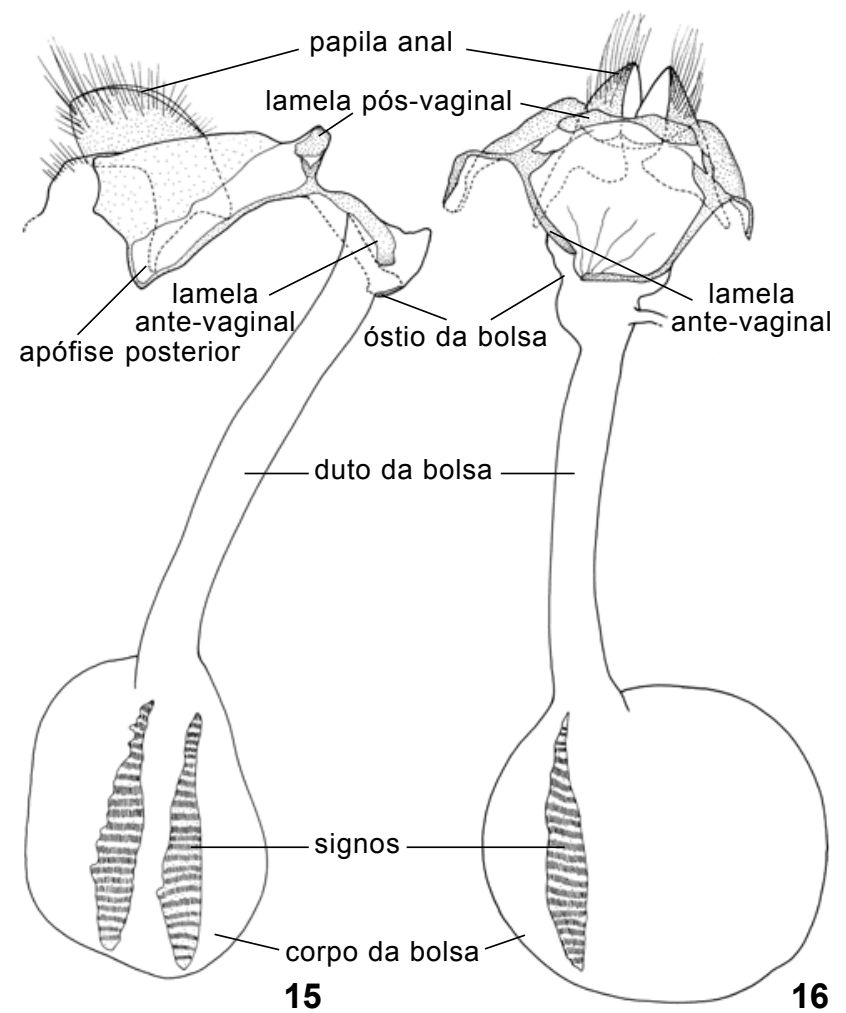

Figuras 15-16. Zaretis itys itylus, genitália feminina: (15) vista lateral; (16) vista ventral.

torácico; mostra uma expansão ântero-lateral projetada ventralmente que se funde ao longo de toda a barra pós-espiracular. Na porção ântero-lateral, uma pequena área arredondada e mais clara, também citada por SoRENSEN (1980) para Glaucopsyche Scudder, 1872, como área de Downey. Esterno II apresenta ânterolateralmente duas regiões mais esclerotinizadas, no centro do esclerito uma região mais esclerotinizada em forma de T invertido, posteriormente e se destacando deste, uma invaginação da membrana forma uma dobra no tegumento, constituindo uma barra retangular de margem anterior bilobada. A fêmea difere do macho por não mostrar pontos de inflexão e apresentar duas porções, onde a primeira, ou anterior é semelhante ao macho e a última, ou posterior é caracterizada por duas regiões centrais menos esclerotinizadas. Segmentos abdominais não modificados, do terceiro ao oitavo nos machos e do terceiro ao sétimo nas fêmeas, apresentam os tergos e esternos como placas transversais sobrepostas às placas posteriores. Na fêmea, o sétimo esterno é triangular lateralmente, provido de inúmeras cerdas. Entre os dois, a pleura membranosa contem os espiráculos abdominais, desde o primeiro até o sétimo segmento.

Genitália masculina constituída pelo tegume (nono tergo) fundido ao unco (décimo tergo). Unco triangular e de comprimento total semelhante a sua maior largura, apresenta uma crista na linha mediana dorsal e porção distal descendente, com ponta curvada para baixo. Tegume projeta-se látero-ventralmente para dar origem ao braço ventral do tegume que se funde ao braço dorsal do saco. A fusão destes dois escleritos é representada por uma banda estreita menos esclerotinizada. A margem anterior do tegume é definida por uma dobra do tegumento que projeta-se externa e posteriormente para inserção da membrana intersegmentar; na margem posterior, na porção ventral, uma projeção lateral, o processo póstero-ventral do tegume é curvado internamente para articular com a parte dorso-basal da valva. Saco (nono esterno) forma a projeção anterior, duas vezes mais longa que larga. Gnato (décimo esterno), em forma de alça, encostado na margem posterior do tegume e sustentando o hilo anal. Valva articulada com o braço póstero-ventral do tegume e com o braço dorsal do saco; retangular, apresenta uma projeção caudal pontiaguda e uma lateral mais suave na margem dorsal; porção esclerotinizada interna e basal forma o sáculo que está articulado anteriormente ao processo posterior do saco; a costa uma dobra dorso-basal interna da valva, com forma de gancho articula com o braço póstero-ventral do tegume. Anteriormente entre as valva, a juxta em forma de semicircunferência responsável pela sustentação do edeago. Cilíndrico e inteiramente esclerotinizado, o edeago, possui duas porções distintas, uma interna e anterior e outra externa e posterior, separadas pela região onde a manica se conecta a estrutura. A anterior, mais esclerotinizada, mostra o bulbo ejaculatório terminal por onde penetra o ducto ejaculatório. A posterior, distalmente com a vesica sem cornuto e quando em repouso retraída como também o prolongamento esclerotinizado lateral direito.

Genitália feminina composta pelos oitavo, nono e décimo segmentos abdominais. O oitavo tergo é representado por duas placas laterais triangulares de pouca esclerotinização, uma a cada lado, unidas ântero-dorsalmente por uma barra em direção ventral à lamela ante vaginal. O oitavo esterno é composto por duas porções, uma posterior ou lamela pós-vaginal caracterizada por uma placa transversal estreitada na porção central, e uma anterior ou lamela ante vaginal com duas barras transversais não fundidas ventralmente, de forte esclerotinização que sustentam o óstio da bolsa. Bolsa copuladora formada pelo óstio, ducto e corpo. Corpo da bolsa esférico e provido de dois signos, placas longitudinais semelhantes, situadas na porção lateral esquerda. Papilas anais, duas placas verticais, formadas pelo nono e décimo segmentos, parcialmente membranosas e com muitas cerdas, possuem na margem anterior duas projeções rudimentares, as apófises posteriores. As papilas anais abrigam o ânus e o oviporo.

\section{Agrias claudina annetta (Gray, 1832) Figs 17-32}

Tergo I composto por porção dorsal com o terço anterior membranoso e os dois terços posteriores esclerotinizados e projetado dorsalmente, de tal forma que aparenta ser uma estrutura independente do restante do abdome. 


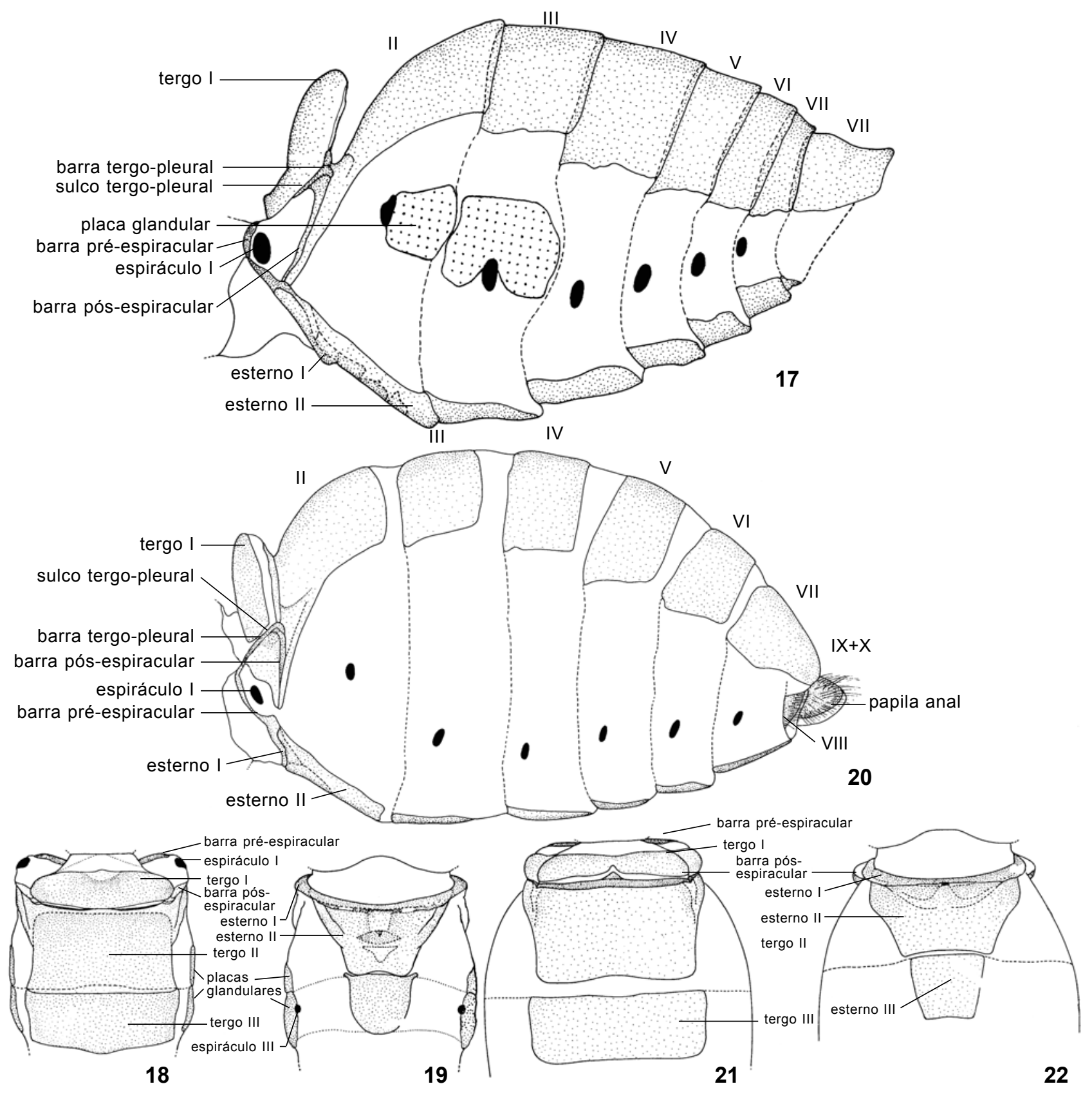

Figuras 17-22. Agrias claudina annetta. (17-19) Abdome do macho: (17) vista lateral; (18) tergos I, II e III; (19) esternos I, II e III; (20-22) abdome da fêmea: (20) vista lateral; (21) tergos I, II e III; (22) esternos I, II e III.

Pleuras II e III com placas glandulares nos machos. A primeira menor, contígua e posterior ao espiráculo II e a segunda contígua, anterior, dorsal e posterior ao espiráculo III. Estas placas também são citadas por CASAGRANDE (1979) para Caligo beltrao (Illiger, 1801), porém em segmentos e posições distintas.
Genitália masculina constituída pelo tegume e unco parcialmente fundidos e com uma profunda constricção que permite identificar cada um dos escleritos. Unco triangular com comprimento aproximadamente o dobro de sua maior largura, com crista na linha media dorsal, porção distal ascendente com ponta curvada para baixo. Projeção anterior do saco uma

Revista Brasileira de Zoologia 21 (4): 905-912, dezembro 2004 


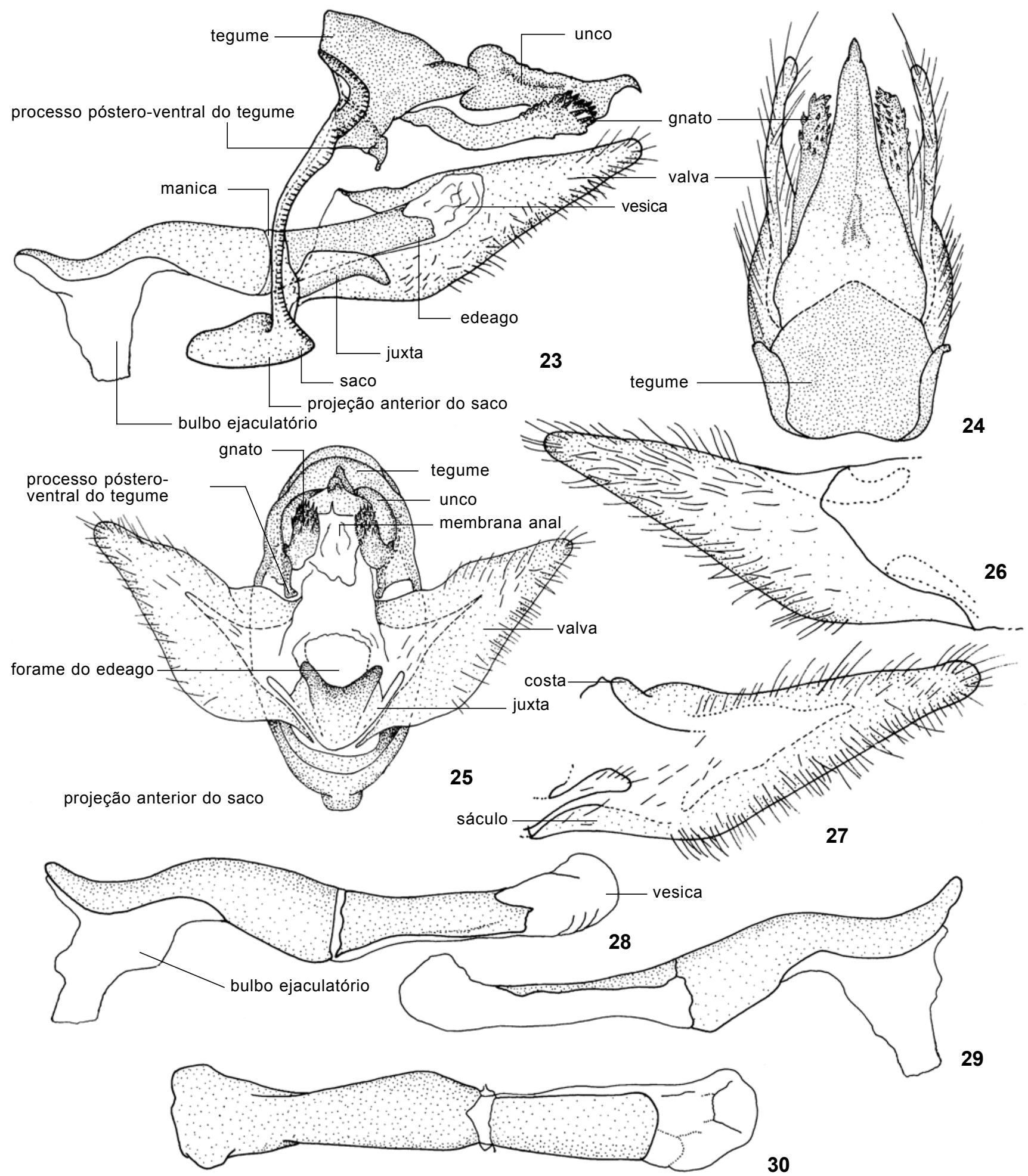

Figuras 23-30. Agrias claudina annetta, genitália masculina: (23) vista lateral; (24) vista dorsal; (25) vista ventral; (26) vista interna da valva; (27) vista externa da valva; (28 - 30) edeago, (28) vista lateral; (29) vista ventral e (30) vista dorsal.

Revista Brasileira de Zoologia 21 (4): 905-912, dezembro 2004 


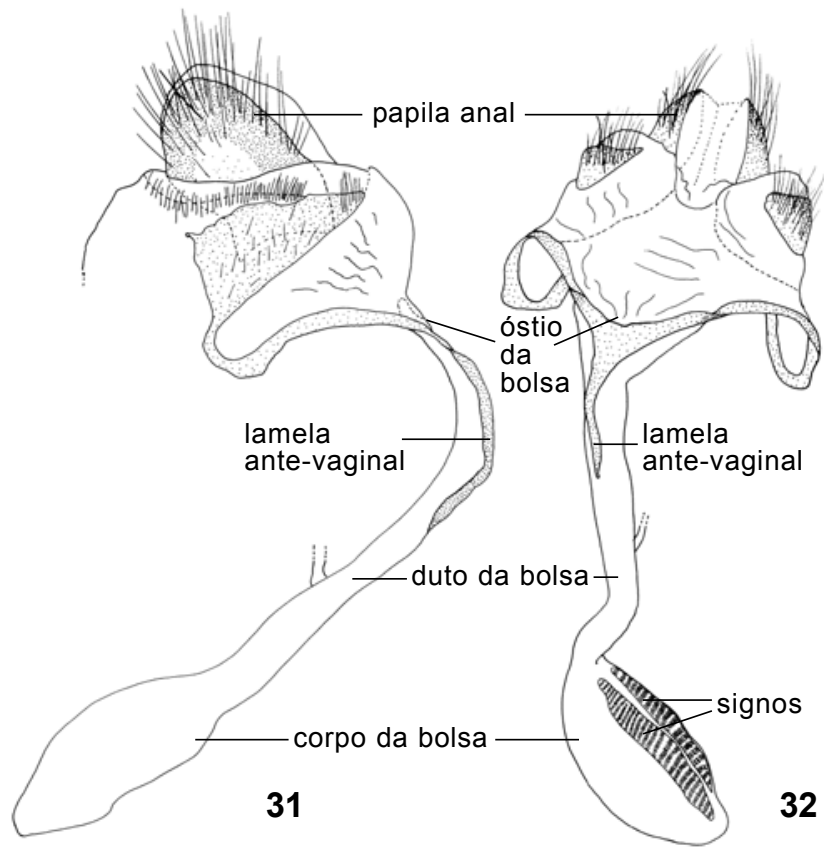

Figuras 31-32. Agrias claudina annetta, genitália feminina: (31) vista lateral; (32) vista ventral. vez mais longa que larga. Gnato formado por duas placas, separadas que sustentam na região basal e lateral anterior a membrana anal, a região distal em forma de clava revestida por espinhos se projeta dorsalmente. Valva triangular com extremidade distal arredondada. Projeção da valva emitida do sáculo contígua à juxta. Juxta em forma de placa trinagular cuja base sustenta a porção ventral do forame do edeago. Edeago, um tubo esclerotinizado apenas nas porções dorsal e lateral esquerda, e na parte centro mediana sem prolongamentos. Vesica totalmente membranosa e sem cornutos. Tanto a vesica como o bulbo ejaculatório estão direcionados ventralmente, como se o edeago tivesse sofrido uma torção de $180^{\circ}$.

Sétimo esterno, nas fêmeas, não distinto dos demais. Genitália feminina com a lamela-antevaginal em forma de " $Y$ " em cuja junção de braços se sustenta o óstio e parte do duto da bolsa. A lamela se projeta anteriormente até aproximadamente a metade do comprimento total do duto. Corpo da bolsa fusiforme e provido de dois signos representados por duas placas longitudinais e semelhantes que ocupam todo o comprimento da porção lateral direita da bolsa. Lamela pós-vaginal ausente.

\section{Comparação morfológica}

Na tabela I relaciona-se resumidamente, as diferenças encontradas entre as espécies em questão.

Tabela I. Comparação resumida sas diferenças encontradas entre as espécies analisadas.

\begin{tabular}{|c|c|c|}
\hline Caráter & Zaretis itys itylus & Agrias claudina annetta \\
\hline Tergo I & $\begin{array}{l}\text { Dois terços anteriores membranosos e o } \\
\text { terço posterior esclerotinizado; não } \\
\text { projetado dorsalmente }\end{array}$ & $\begin{array}{l}\text { Terço anterior membranoso e os dois terços } \\
\text { posteriores esclerotinizados; projetado } \\
\text { dorsalmente }\end{array}$ \\
\hline Placas glandulares & Ausentes & Presentes \\
\hline Esterno VII da fêmea & $\begin{array}{l}\text { Triangular lateralmente, diferenciado dos } \\
\text { demais segmentos }\end{array}$ & Não diferenciado dos demais segmentos \\
\hline Tegume/ unco & Fundidos com tênue delimitação & Fundidos mas com significativa constricção \\
\hline $\begin{array}{l}\text { Razão entre o comprimento total e a } \\
\text { largura máxima do unco }\end{array}$ & 1 & 2 \\
\hline Extremidade distal do unco & Descendente & Ascendente \\
\hline Formato do gnato & Alça fundida & Duas placas separadas \\
\hline Formato da valva & Retangular & Triangular \\
\hline $\begin{array}{l}\text { Projeção oriunda da valva em direção ao } \\
\text { sáculo }\end{array}$ & Distinta da juxta & Contígua à juxta \\
\hline Formato da juxta & Semicircunferência & Triangular \\
\hline $\begin{array}{l}\text { Posição das aberturas do bulbo } \\
\text { ejaculatório e da vesica }\end{array}$ & Dorsal & Ventral \\
\hline Bulbo ejaculatório em relação ao edeago & Apical & Pré-apical \\
\hline $\begin{array}{l}\text { Esclerotinização da porção posterior e } \\
\text { externa do edeago }\end{array}$ & $\begin{array}{l}\text { Tubo inteiramente esclerotinizado com } \\
\text { prolongamentos que se retraem com a } \\
\text { vesica }\end{array}$ & $\begin{array}{l}\text { Tubo esclerotinizado na parte dorsal e } \\
\text { lateral esquerda sem prolongamentos }\end{array}$ \\
\hline Lamela pós-vaginal & Presente & Ausente \\
\hline Lamela ante-vaginal & Fendida ventralmente & Contígua ventralmente \\
\hline Corpo da bolsa & Esférico & Fusiforme \\
\hline Posição dos signos no corpo da bolsa & Lateral esquerda & Lateral direita \\
\hline
\end{tabular}




\section{AGRADECIMENTOS}

Agradecemos aos amigos e colaboradores Guilherme Pereira de Almeida Neto (Conceição dos Ouros, MG), Herbert Miers (Joinville, SC) e Ivo Rank (São Bento do Sul, SC) pela disponibilização de informações e exemplares de suas coleções.

\section{REFERÊNCIAS BIBLIOGRÁFICAS}

Bethune- Baker, G.T. 1891. I. Notes on the genitalia of a gynandromorphous Eronia hippia. Transctions of the Entomological Society of London: 1-6.

BilotTa, I.G. 1994. Morfologia comparada do abdome das espécies sulbrasileiras de Morphinae (Lepidoptera, Nymphalidae). Revista Brasileira de Zoologia, Curitiba, 11 (4): 737748.

Bizarro, J.M.S.; M.M. Casagrande \& O.H.H. Mielke. 2003. Morfologia externa de Thyridia psidii cetoides (Rosemberg \& Talbot). IV. Abdome e apêndices (Lepidoptera, Nymphalidae, Ithomiinae). Revista Brasileira de Zoologia, Curitiba, 20 (4): 681-684.

BRoCK, J.P. 1971. A contribution towards an understanding of the morphology and phylogeny of the Ditrysian Lepidoptera. Journal of Natural History, London, 5: 29-102.

Casagrande, M.M. 1979. Sobre Caligo beltrao (Illiger). III (sic) Morfologia externa do adulto - abdome (Lepidoptera, Satyridae, Brassolinae). Revista Brasileira de Biologia, Rio de Janeiro, 39 (3): 711-716.

Chapman, T.A. 1911. On the scaphium of Gosse. Entomological Record \& Journal Variation, London, 23: 285-288.

DOHERTY, W. 1886. A list of Butterflies taken in Kumaon. Journal Asiatic Society of Bengal 55 (2): 103-140.

EнRLICH, P.R. 1958a. The integumental anatomy of the monarch butterfly Danaus plexippus L. (Lepidoptera: Danaidae). Uni- versity of Kansas Science Bulletin, Lawrence, 38 (18): 13151349.

Mielke, C.G.C.; O.H.H. MielKe \& M.M. Casagrande. 2004a. Estudo comparado da morfologia externa de Zaretis itys itylus (Westwood) e Agrias claudina annetta (Gray) (Lepidoptera, Nymphalidae, Charaxinae). I Cabeça, apêndices e região cervical. Revista Brasileira de Zoologia, Curitiba, 21 (2): 357-369.

. 2004b. Estudo comparado da morfologia externa de Zaretis itys itylus (Westwood) e Agrias claudina annetta (Gray) (Lepidoptera, Nymphalidae, Charaxinae). II Tórax e apêndices. Revista Brasileira de Zoologia, Curitiba, 21 (3): 421-433.

NiculesCu, E.V. 1973. L'armure génitale chez les Lépidoptères. Supplement du Bulletin de la Societé Entomologique de Mulhouse, 96p.

Nielsen, E.S. \& I.F.B. Common. 1991. Lepidoptera (Moths and butterflies), p. 817-915. In Csiro (Ed.). The Insects of Australia. Carlton, Melbourne University Press, 1137p.

Ogata, M.; Y. Okada; H. Okagaki \& A. Sibatani. 1957. Male genitália of Lepidoptera: moorphology and nomenclature III. Appendages pertaining to the tenth somite. Annals of the Entomological Society of America, New York, 50 (1): 237 244.

PierCe, F.N. 1909. The genitalia of the Noctuidae. Liverpool, A.W. Duncan Printer, 88p.

- 1914. The genitalia of the Group Geometridae of the Lepidoptera of the British Island. Liverpool, XII+88p.

Scoвle, M. 1992. The Lepidoptera form, function and diversity. Oxford, Natural History Museum PublicationsOxford University Press, 404p.

SoRENSEN, J.T. 1980. An integumental anatomy for the butterfly Glaucopsyche lygdamus (Lepidoptera: Lycaenidae): a morphological terminology and homology. Zoological Journal of the Linnean Society, London, 70: 55-101.

Recebido em 06.VI.2003; aceito em 12.XI.2004. 